\title{
Popular perceptions of emerging influences on mortality and longevity in Bangladesh and West Bengal
}

\author{
Sajeda Amin \\ Population Council \\ Alaka Malwade Basu
}

Follow this and additional works at: https://knowledgecommons.popcouncil.org/departments_sbsr-pgy

Part of the Demography, Population, and Ecology Commons, Family, Life Course, and Society Commons, and the International Public Health Commons How does access to this work benefit you? Let us know!

\section{Recommended Citation}

Amin, Sajeda and Alaka Malwade Basu. 2004. "Popular perceptions of emerging influences on mortality and longevity in Bangladesh and West Bengal," Policy Research Division Working Paper no. 186. New York: Population Council. Version of record: https://doi.org/10.1080/0032472042000272393 


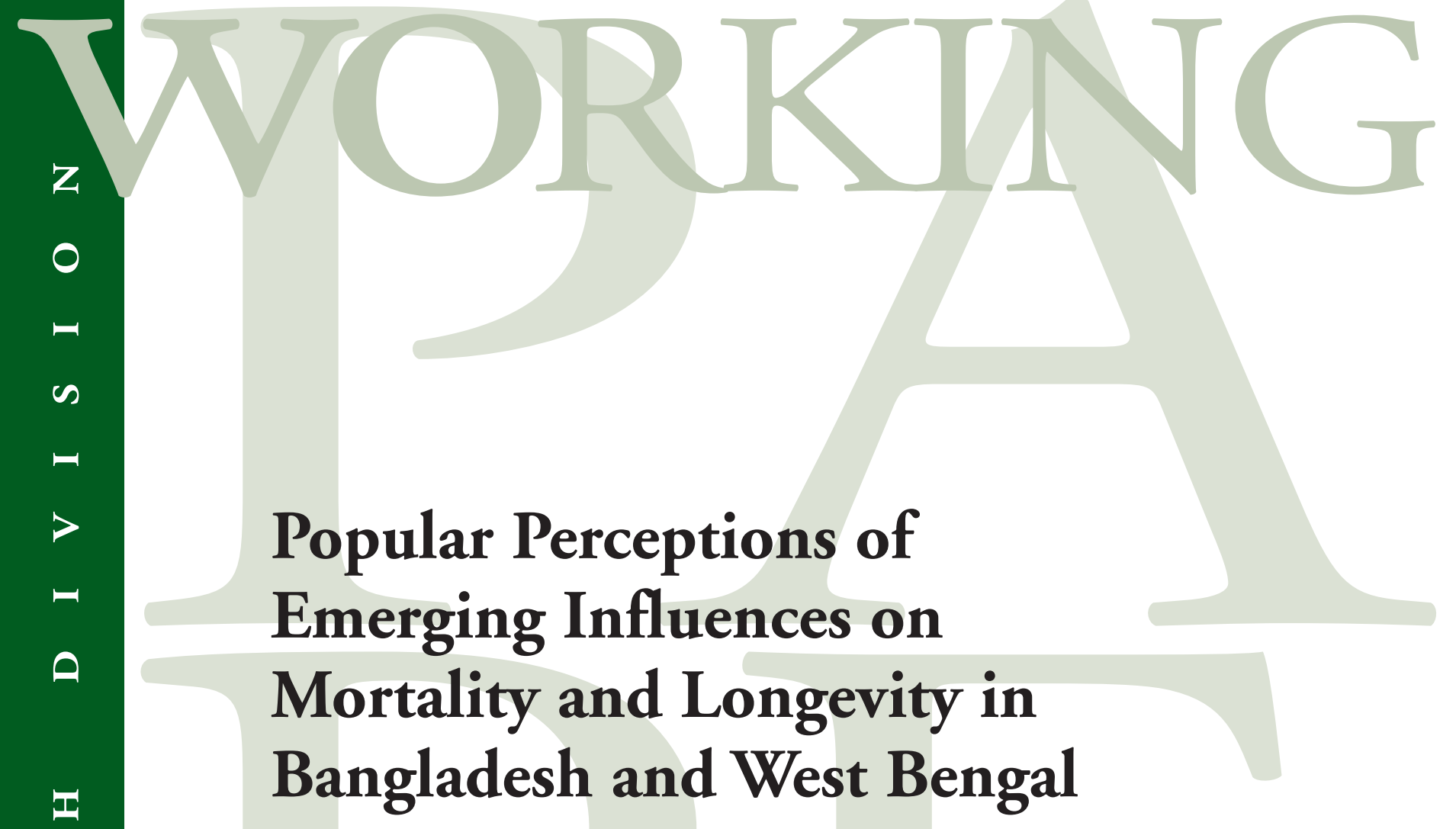

U

$\simeq \quad$ Sajeda Amin

Alaka M. Basu

$\varangle$

[디

2004 No. 186

$\infty$

[디

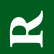

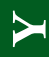

$\cup$

$\mapsto$

$\mapsto$

0

A

12 Population Council 


\title{
Popular Perceptions of Emerging Influences on Mortality and Longevity in Bangladesh and West Bengal
}

\author{
Sajeda Amin
}

Alaka M. Basu

Sajeda Amin is Senior Associate, Policy Research Division, Population Council. Alaka M. Basu is Associate Professor of Demography, Department of Sociology, Cornell University, Ithaca, NY. An earlier version of this paper was presented at the 2003 Annual Meetings of the Population Association of America in Minneapolis, MN. Correspondence should be addressed to Sajeda Amin, Senior Associate, Population Council, One Dag Hammarksjold Plaza, New York, NY 10017. The fieldwork on which this paper is based was supported by a grant from the Rockefeller Foundation to Cornell University.

This material may not be reproduced without written permission from the authors. For a list of Policy Research Division Working Papers, including those available for downloading in PDF format, see www.popcouncil.org/publications/wp/prd/rdwplist.html. 


\begin{abstract}
Although new environmental and pathological threats to human survival and longevity have been documented, relatively little is known about how these threats are perceived in the popular imagination. During fieldwork in rural Bangladesh and West Bengal, India, researching the changing costs of and motivations for reproduction, the authors included survey questions on respondents' perceptions of changing mortality. Child-mortality levels were perceived to have fallen drastically in recent times, but for the middle-aged and the elderly, the past was seen as a better time in terms of health and survival. The decline in adult health is attributed to environmental deterioration and lifestyle changes associated with modernization. This paper explores the objective validity of and subjective reasons for this unexpected worldview. References to pesticides and chemical fertilizers as causes of death abound, but mention of other emerging health threats including the HIV/AIDS pandemic, dengue, and toxic levels of arsenic in the water table is conspicuously absent.
\end{abstract}


Perceptions about a risk or threat are often as important a determinant of behavior and consequent mortality outcomes as the fact and nature of the threat itself. Individual and communal perceptions about mortality influence not just mortality; in the demographic literature they are posited to be an important determinant of fertility as well (Cleland 2001). This paper explores trends in human survival and longevity as they are perceived in the popular imagination in Bangladesh and West Bengal.

Some unexpected incidental findings that emerged in the course of demographic interviews conducted in rural Bangladesh and the state of West Bengal in India piqued the authors' curiosity. During individual and focus-group interviews with respondents of both sexes that focused primarily on the changing costs of and motivations for reproduction, we included questions about perceptions of changing mortality. The demographic literature hypothesizes that falling rates of infant and child mortality are an important determinant of declining fertility rates (Cleland 2001), implying that community and individual perceptions about improvements in child survival rather than the demonstrable fact of this improvement provide an impetus to control fertility. The interview respondents and focusgroup participants said, almost without exception, that although childhood mortality has declined, adult mortality has increased.

\section{BACKGROUND}

As Montgomery (2000) notes, demographers have paid little attention to perceptions of mortality risk despite the routine textbook assumption that perceptions of mortality change have an important bearing on fertility change. In addition to expanding on this assumption, an understanding of how perceptions are formed may offer insights into the process of the diffusion of knowledge and ideas in a society. When ordinary people make judgments about trends, they are likely to bring a variety of tools to the task. These include their own experiences and the experiences of those around them. Assessing rates and probabilities by observing numerators and denominators is a complex undertaking. People's ability to assess probability is imperfect at best and especially difficult during periods of change. Thus, it is likely that individuals rely on the assessment of others and that the diffusion of knowledge plays an important part in formulating judgments. Individual experience is likely to be but one component of perception. Social learning is a major factor, but such learning often suffers from prejudice and bias. Montgomery identifies one kind of bias derived from a time lag in perception; as a result, the extent of recent mortality decline is not fully comprehended.

Few studies have attempted to assess adult perceptions of mortality among the elderly. Hurd and McGarry (1995) found considerable agreement between subjective and objective measures of mortality in the United States in a highly educated sample, but Mirowsky (1999) found perceptions to vary systematically with race and socioeconomic class. We are not aware of similar studies conducted among laypersons in developing countries. Chatterjee (1998) has studied perceptions of mortality among the elite over the course of 
several centuries by analyzing the writings of social commentators and influential reformers in Bengal and finds evidence of a remarkable consistency in how mortality is perceived to be rising in recent times relative to the past. This perception of rising mortality is as characteristic of writers working in the mid-eighteenth century as it is of commentary in the midtwentieth century when demographic trends were clearly in the opposite direction.

Chatterjee's interpretation of this perception reflects ideas described by Greenough (1983) of a past characterized by abundance, virtue, and glory contrasted with a present of poverty and moral degeneration. Chatterjee's explanation of why perceptions so consistently conflict with demographic reality invokes a theory of the politics of ideas suggesting that intrinsic to a postcolonial consciousness is a profound skepticism that views "modernity" as being of foreign origin and therefore never owned by the colonized. By extension, this modernity is also not worth owning because it is inferior to the traditions of the past that it seeks to replace.

\section{DATA AND METHOD}

The qualitative data presented in this analysis are drawn from a larger study of cultural theories of fertility decline in the two Bengals. A total of 32 focus-group interviews having between six and ten respondents each were conducted in nine districts, four in Bangladesh and five in West Bengal in 1997-98. Groups were homogeneous in terms of sex and religious background. The districts chosen were Gaibanda, Kishorganj, Noakhali, and Rajshahi in Bangladesh and Birbhum, Malda, Murshidabad, Nadia, and Purulia in West Bengal. They were selected purposively to represent areas at the extremes of change in fertility behavior. Gaibandha, Malda, Murshidabad, Nadia, and Rajshahi have a high prevalence of contraceptive use, while the other districts are at the low end of the level of use for their regions. The comparison of Bangladesh and West Bengal was motivated by the larger question of whether demographic change is contained by national borders. District selection was based on multilevel analysis of contraceptive use whereby outlier districts were identified (see Amin et al. 2002). The choice of areas to study was motivated by a desire to understand the considerable regional variation in contraceptive behavior within West Bengal and Bangladesh.

Individual interviews were also conducted in the same districts, stratified by sex and by the two dominant religions, Islam and Hinduism. The interviews were conducted by experienced local researchers who were recruited from reputable social survey firms. Individual and focus-group sessions were conducted in Bangla, the language of both regions.

Typically, they lasted for two to two and a half hours and were taped, transcribed, and later translated into English. Because local variations in dialect are considerable, particular attention was given to the language of the interviews and discussions to ensure clear communication between respondents and interviewers.

The general level of responsiveness and enthusiasm during the discussions varied strikingly by sex. Men were more likely than women to engage in conversation and offer 
divergent opinions within the groups. No notable differences by religion or country were observed in respondents' ability to comprehend or answer questions, although educational levels were higher in West Bengal than in Bangladesh. Differences were detectable in the general values and attitudes expressed by those living in areas of high contraceptive use in relation to those expressed by residents of areas where contraceptive use was low. (Analysis of these differences can be found in Basu and Amin 2000.)

\section{RESULTS}

In the last half of the twentieth century, both Bangladesh and West Bengal experienced rapid mortality decline. According to statistics published in 2002 by the World Health Organization based on official national data, life expectancy at birth in India (including the area that is now Bangladesh) rose from around 30 years in the 1930s to more than 60 years in 2000 (see Figures 1a and 1b). Infant mortality fell from 250 deaths per 1,000 live births to around 70 deaths per 1,000 (Bairagi et al. 1999; DHS + DIMENSIONS 2000). Although much of the change in life expectancy at birth is attributable to declining infant and child mortality, decline in mortality is by no means limited to the early years of life. Death rates have declined across the age range, and life expectancy has increased substantially at every age. Although mortality data in this region are of notoriously poor quality, some unusually high-quality longitudinal data collected over the past 40 years from a small rural area of Bangladesh show that the region continues to witness rapidly declining mortality among both young and old (see Figures $2 a$ and $2 b$ ).

In our focus-group interviews, respondents agreed unanimously that child-mortality levels had fallen drastically in recent times. Taken together with the fall in birth rates that this population has been experiencing, the hypothesis in demography that improved child survival drives fertility decline is not contradicted. The reasons given for the decline in child mortality were uniform across focus groups and consistent with the assessment of public health experts. Factors identified included preventive measures such as vaccination against childhood diseases. Respondents specifically attributed the decline to an increase in antitetanus vaccination of pregnant mothers, the expansion of medical care facilities for women and children, door-to-door service delivery by health-care workers, and changing parental attitudes about medicine. On this last point, respondents expressed the feeling that although parents formerly relied on witchcraft, now they trust modern medicine.

In general, the focus-group discussants were well-informed about the reasons for the decline in child mortality. The discussions also reflected surprising agreement among the diverse group of respondents about mortality trends, as well as a high degree of sophistication in awareness of public health. These assessments were not different from the conclusions drawn on the basis of more objective or scientific analysis. The participants in several focus groups discussed change in the incidence of tetanus-related deaths and the causes for the change, consistent with the identification by demographers and medical anthropologists 
Figure 1a Life expectancy among men, India and Bangladesh, 1901-2000

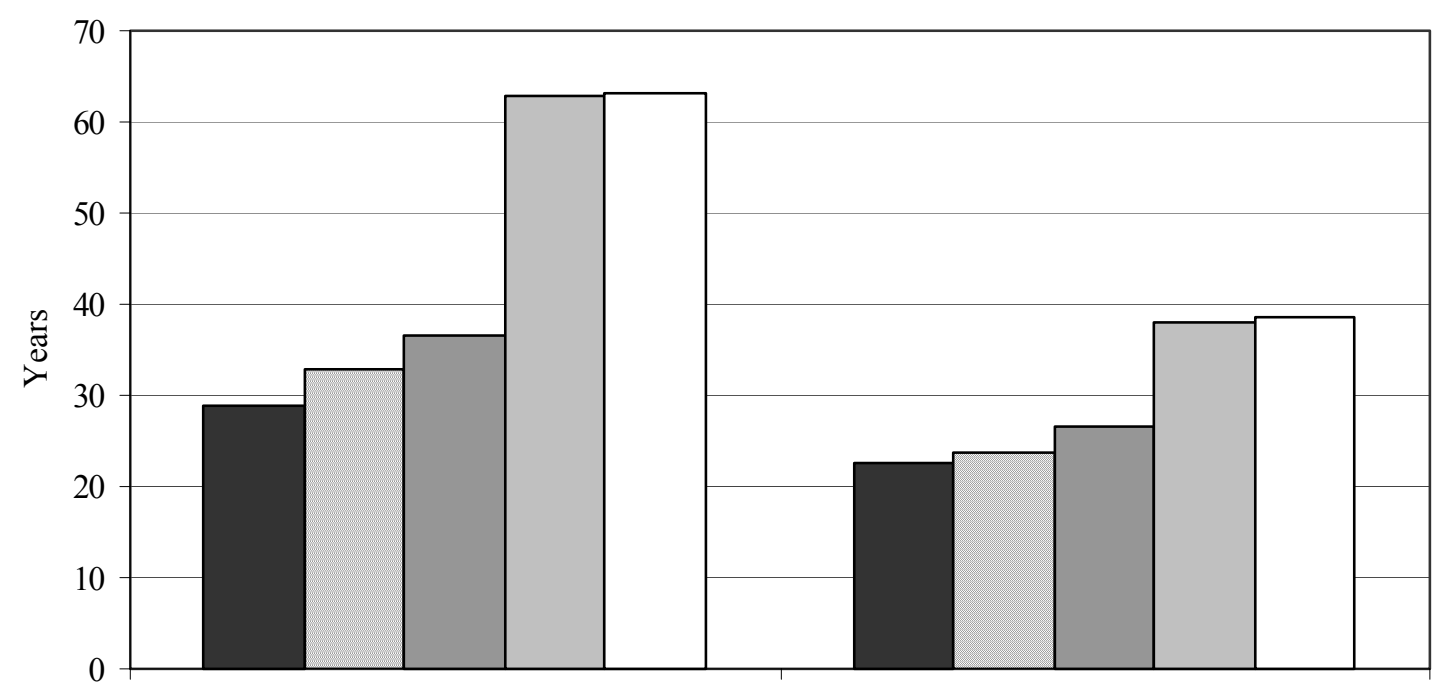

Life expectancy at birth

Life expectancy at age 30

$\begin{array}{lcccc}\square \text { India } & \square \text { India } & \square \text { India } & \square \text { India } & \square \text { Bangladesh } \\ \text { 1901-11 } & 1921-31 & 1941-50 & 2000 & 2000\end{array}$

Source: WHO (2002).

Figure 1b Life expectancy among women, India and Bangladesh, 1901-2000

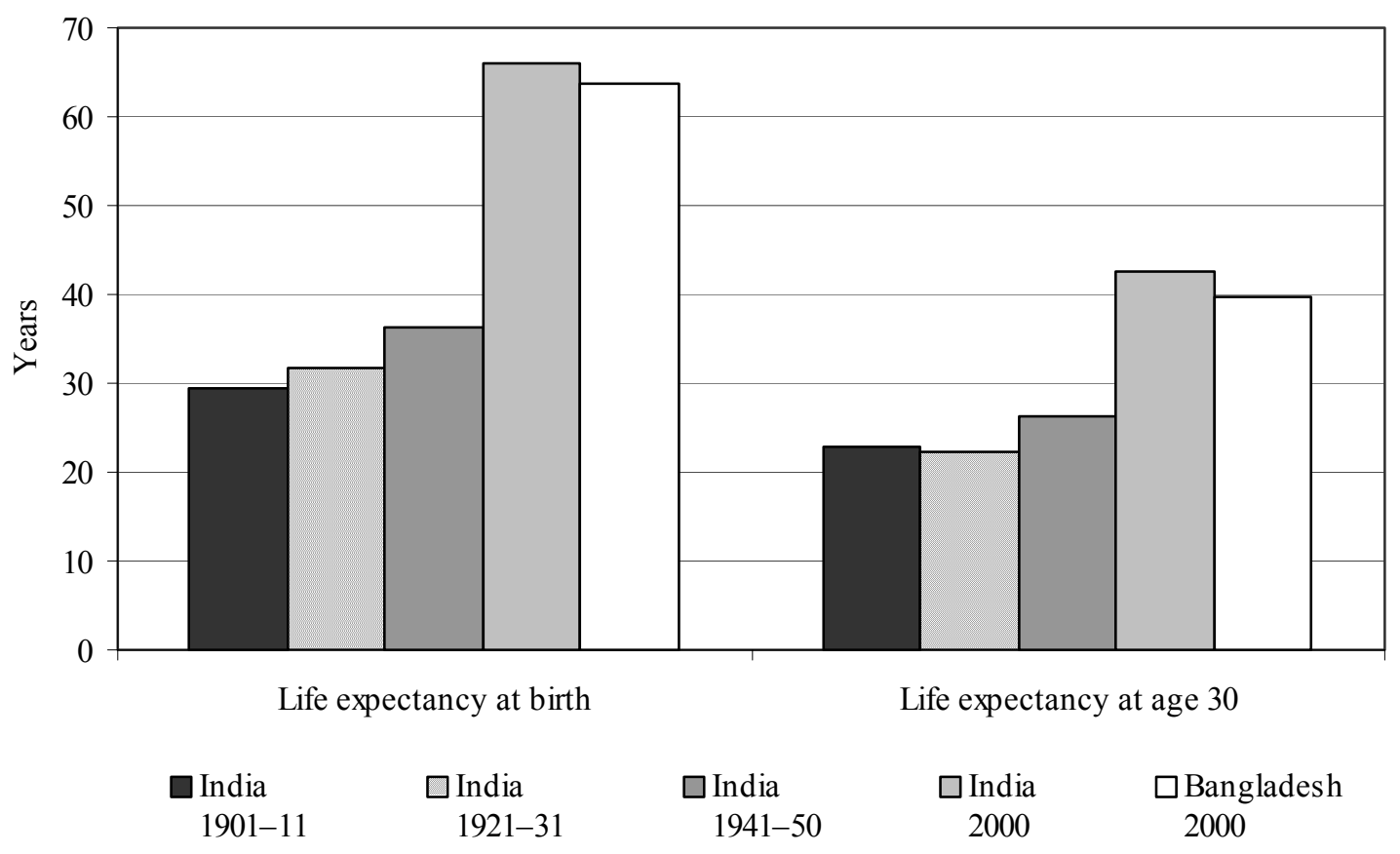

Source: WHO (2002). 
Figure 2a Life table showing probability of survival $\left(1_{x}\right)$ from birth to specific ages, by sex, Matlab, Bangladesh, 1976-2000

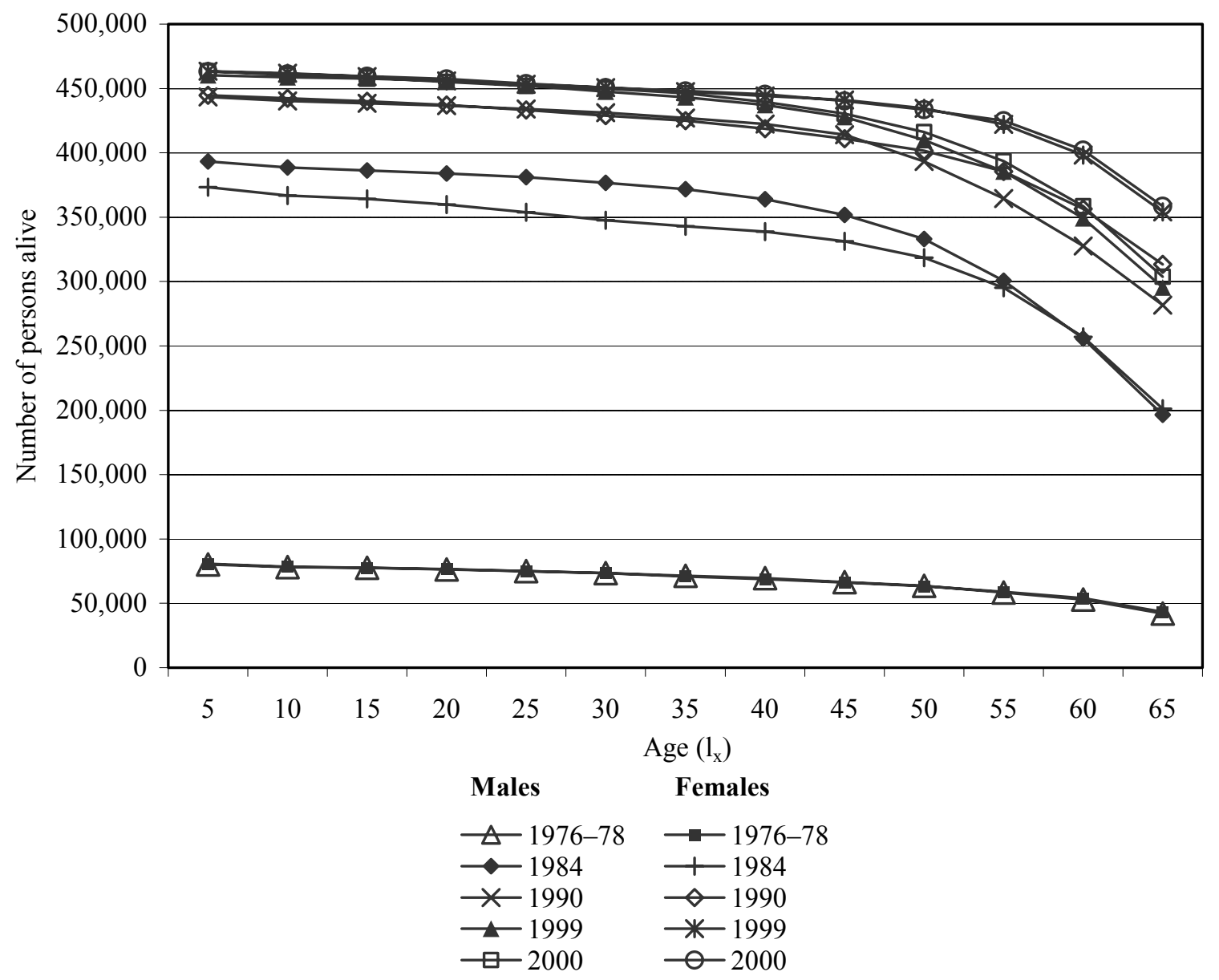

Sources: Ruzicka and Chowdhury (1978); Samad et al. (1979); ICDDR, B (1991, 1994, and 1996); Mostofa et al. (1996). 
Figure 2b Life table showing average number of years of life remaining $\left(\mathrm{e}_{\mathrm{x}}^{0}\right)$ at specific ages, by sex, Matlab, Bangladesh, 1977-90

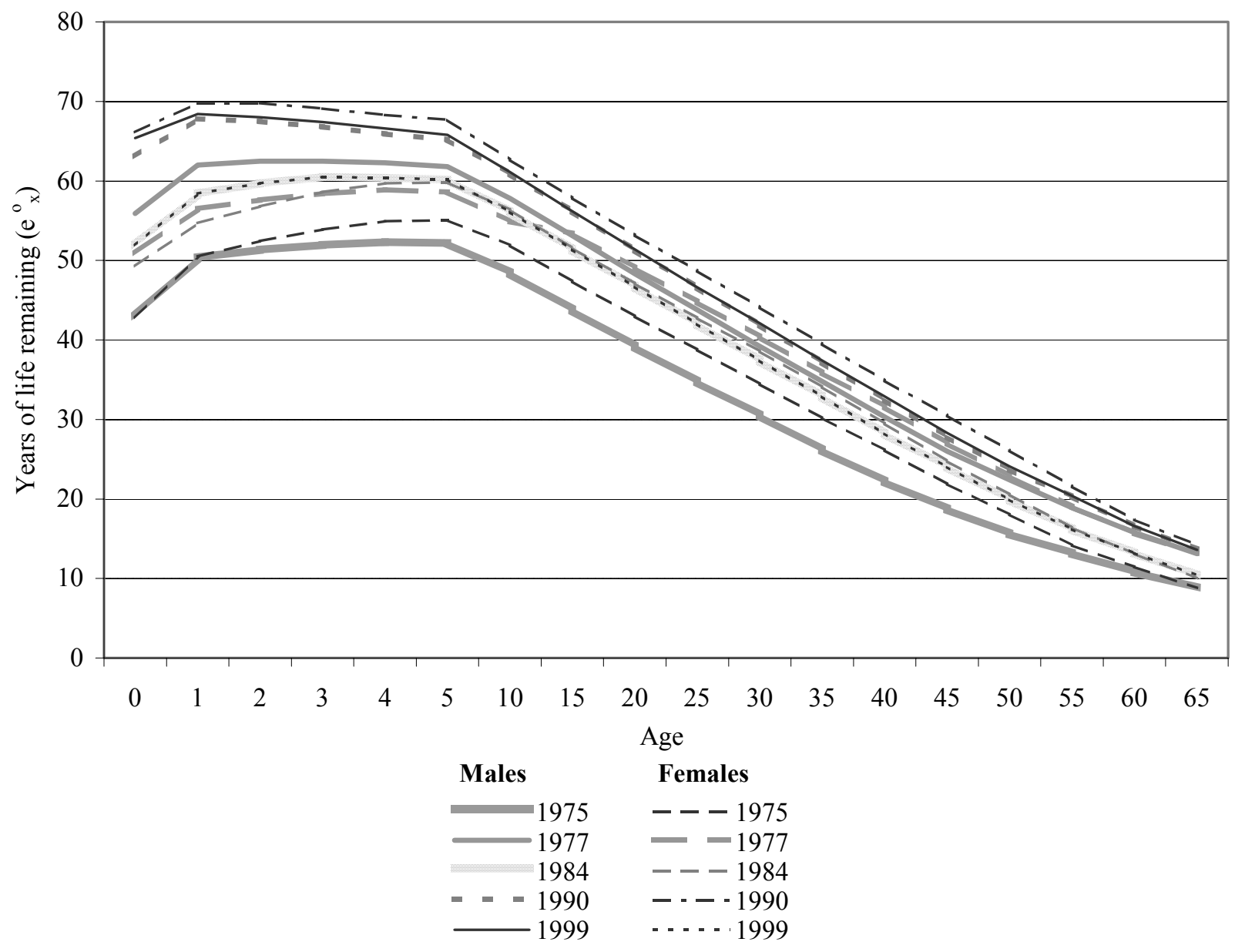

Sources: Ruzicka and Chowdhury (1978); Samad et al. (1979); ICDDR, B (1991, 1994, and 1996); Mostofa et al. (1996). 
of unhygienic birth practices as a major cause of high neonatal mortality in the past and of a successful campaign to immunize mothers as a major cause of decline in this mortality (Amin 1995; Koenig et al. 1998).

Increased immunization against childhood diseases was also mentioned frequently in our interviews. Immunization rates have improved significantly; coverage against the major diseases by 2000 is reported to be greater than 90 percent in Bangladesh and 70 percent in India (WHO 2000). Respondents also identified fertility decline as a factor in increased child survival. Similarly, several studies conducted at the International Centre for Diarrhoeal Disease Research, Bangladesh (ICDDR,B) suggested that the reduction of births occurring at close intervals has contributed to rapid mortality decline, particularly in the 1990s (Le Grand and Phillips 1996; DHS + DIMENSIONS 2000). Overall, the rural respondents in this study seem to have had some remarkable insights concerning the determinants of high and falling child mortality - a testimony, perhaps, to the effective public health campaigns in the region.

Some illustrations of respondents' assessment of mortality trends are presented in Box 1.

Box 1 Responses to the question, "Has child mortality increased or decreased in the recent past in your area?"

The infant death rate has gone down in comparison to earlier times. Earlier, there was no hospital facility, and because of communication problems, it was not possible to go out for better treatment. Now all these facilities are available.

[Child mortality] has decreased; the government is taking a number of steps, and the parents are also becoming conscious.

Health workers are very active now. They make necessary arrangements for shifting the patients to the hospitals or elsewhere.

Actually, the death [of children] is because of tetanus. Now, tetanus death is much reduced because of vaccinations and injections.

Earlier, the umbilical cord used to be detached by a bamboo twig, which at times resulted in sepsis and more deaths. Now the blade is sterilized in hot water for this purpose.

In earlier days, the death of a child was termed "possession by an evil spirit."

The focus-group participants and individual-interview respondents added some unexpected comments, however. They informed us that although children are now less likely to die than they were in the past, the same cannot be said about adults' survival prospects. In interview after interview, respondents asserted that adults today die earlier than they did 
in the past; that the chances of living to a ripe old age have greatly diminished in recent years; and that there are fewer wise old men and women to turn to now (see Box 2). The research team was taken aback by these responses, and they asked the question in various ways to learn whether these views held. They asked whether "the past" means one or two generations ago, ${ }^{1}$ and phrased questions suggesting that mortality has declined for adults. A couple of respondents reevaluated their position, but the great majority persisted in their conviction that adult mortality had increased. The question about adult mortality was asked in the following ways:

Has adult mortality increased or decreased?

Has life expectancy increased or decreased?

Are adults more likely to die now than in the past?

Are there more old people now relative to young adults?

Are there more people now who live to an old age than did in the past?

Box 2 Responses to the question, "Has adult mortality (life expectancy) increased or decreased?"

[Adults'] longevity is much reduced now. People do not survive beyond 50 to 60 years, whereas earlier, people used to live up to 80 or 90 years.

In comparison to earlier days, longevity has decreased. Previously, people used to survive longer, but now they are dying at young ages.

From that angle, medical facilities and hospitals have grown many times, as a result of which very few people die of illness or disease. However, nobody survives as long as 80 to 90 years.

Previously, people used to survive for more than 100 years.

Now more people are dying at younger ages.

Earlier, people used to live as long as 100 to 105, but nowadays nobody lives that long.

[Adults are] suddenly dying.

The widows I saw [in the past] were mostly those who became widows in their childhood (bal-Bidhaba). There were also some aged widows. Now, nobody survives as long as 80 years. In my childhood, I saw people who were 90 yeas old, but now people die at 65 years.

They are dying early. They are not reaching advanced ages.

Life expectancy has declined. Earlier, people used to live for 100 years, 150 years, and now some people die at 50 years, some at 60 years, and even at 20 years. 
Regardless of how the question was phrased, respondents gave the opinion that adult life expectancy or longevity had declined, that more people lived for 80 years or longer in the past than do now, and that adult mortality has increased. In the pilot focusgroup discussions when the questions were asked without differentiating between child and adult mortality, the respondents insisted on distinguishing between the death of children and that of adults because they were contrary trends. After respondents made the distinction clear, the team asked about child and adult mortality in separate questions.

The responses were similar regardless of whether the question was asked about death rates, life expectancy, or longevity (ayu or hayat, in local terminology). Respondents offered a host of opinions about the reasons for increased adult mortality. Some suggested that the timing of death was less predictable than it had been in times gone by ("people die suddenly"), but few made specific reference to instances of adults' death.

The perception that longevity has declined is so contrary to demographic research findings that we felt compelled to explore the issue further in our qualitative data. Because practically no variation exists in this assessment of mortality trends regardless of the background of the respondent or how the question is posed, we place our greatest emphasis on respondents' reasons for their assessment.

Overwhelmingly, respondents identified a decline in the quality of food as a reason why people are not as healthy as they were in the past and do not live as long as they used to (see Box 3). A summary of the reasoning behind their responses would be as follows: Food is less healthful now because it is grown with poisonous fertilizers and pesticides; food is grown for sale in the market rather than for consumption by the farmer's own family and, therefore, is grown with less care; and the lifestyle that is adopted for producing food for the market rather than for subsistence has mental and physical consequences. That lifestyle leads to stress, which in turn leads to cancers, allergies, ulcers, and diabetes. Stress and market-oriented lifestyles expose young people to risky behaviors and to abuse of drugs and other substances. One group mentioned the rise in the use of addictive substances, including heroin, alcohol, and ganja (marijuana), but most focus-group participants spoke of degeneration in more general terms. Discussions frequently led to the conclusion that in the past people were more God-fearing and pious.

The argument respondents advanced concerning food quality referred specifically to the poorer nutrient, protein, and vitamin content of contemporary foodstuffs, claiming these deficiencies to be characteristics of hybrid, high-yield varieties of rice, grain, and vegetables that are grown now instead of indigenous ones in order to ensure greater production. Repeated references were made to the decline in good, "natural," and "organic" farming practices and the rise of harmful modern and imported methods of production. In Bangladesh and West Bengal, equating natural foods with indigenous ones and artificial or deficient foods with imported ones is not difficult. New varieties are easily identified by their foreign names, their sources (agriculture extension services), and their distinct requirements for fertilizer and pesticides. 
Box 3 Focus-group participants' stated reasons for the perceived decline in adult survival: Diminished food quality

Cow dung, which used to be applied in the field, was of pure quality, but now the fertilizers and manures that come from outside for increased crop production are all adulterated and poisonous.

Proteins and vitamins in food items have decreased because of fertilizer usage.

Those powerful fertilizers are harmful.

Earlier, vitamins were available in the food, but everything is now adulterated.

The rice grown with chemical fertilizer is causing gastric illness.

These urea and phosphate [additives], are they good?

Earlier, people applied less chemical fertilizer to their fields; now excessive fertilizer is being used. Earlier, ailments were few, but now there are more.

Milk, jaggery, [and other foods] had more nutritional value in earlier times because these were consumed in pure condition.

Earlier, cultivation used to be with organic manures, and now we are taking poisons.

The focus-group participants' responses suggested not only that the deterioration of the intrinsic quality of food products is apparent but also that the modern processes by which food is produced is unhealthy for the producer and that market-bought food is inferior because it is produced with less care (see Box 4). They made specific references to increased production for the market facilitated by new food varieties with a high yield per acre, production that has replaced subsistence agriculture. Two distinct ways were mentioned in which the production process is unhealthy for the consumer and for the producer: A producer who is motivated to sell will not consume the best of his products. Moreover, he is motivated to adulterate the product to increase his profit. Thus the milkman mixes his milk with polluted water and adulterates the bottles of ghee that he sells in the market at prices that he himself would not be able to afford. The fisherman sells his largest catch and keeps only the smaller fish for himself and his family. In his haste to make a profit, the farmer does not grow his rice and vegetables with care. In the process, everyone loses. 
Box 4 Focus-group participants' stated reasons for the perceived decline in adult survival: Subsistence farming versus production for the marketplace

By prosperity, I mean that in the past people used to grow rice paddies [and other food] properly and used to eat proper food. Nowadays, production is greater, but people do not benefit from it. With the increase in population, prosperity has declined.

Earlier, there was prosperity in the family, although there were large families. Now there is prosperity all around, but we see less prosperity in the family.

We are not able to see any good fruits nowadays, whereas earlier, people not only saw it, they ate it, too. Earlier, people never used to take rice [have a meal] without milk, whereas [now], we cannot have a glimpse of it.

Now ghee made of cow's milk is expensive. Also, it is not available. Only those who have money can buy it.

If I [caught the fish], I may not be eating it; somebody else will eat it if I sell it. But in this area, you do not get to have it. [A big modern] net has destroyed the fishes here.

Our respondents made the point that producing food for profit and consuming produce from a market rather than from one's own farm leads to high stress, a poor lifestyle, and moral degeneration (see Box 5). Most villagers still live at a considerable distance from the marketplace, so that the increase in commercialization of food likely increases the time people spend marketing produce. In Bangladesh and West Bengal, a growing number of permanent marketplaces are replacing the older tradition of less frequent and impromptu or seasonal weekly markets (haats). The growth of marketplaces has implications for individual lifestyles and how people spend time. Visiting the marketplace is an important pastime for men, and as in many other societies, it is a place to exchange gossip, ideas, and information as well as to shop for goods and services. Markets expand the social space of villages and are, therefore, held responsible for much that is changing in society.

The focus-group respondents perceived the past in positive terms. As Greenough (1983) suggests, the general feeling seems to be that in the past, life in Bengal was a time of abundance. The food was pure, produced with care, and plentiful. Overpopulation has depleted the ponds of fish and the storehouses of rice. Because there were fewer people in the past, everyone could live well (see Box 6). Respondents' assessments of the relative abundance of the past, similar to Greenough's accounts of Bengali villagers' assessments of higher availability of food and resources per capita in the past, are linked directly to the population explosion. Like Greenough, we did not find much evidence in focus-group re- 
sponses that current catastrophic threats loom large in the minds of most participants. In fact, some respondents remarked that they consider the threats of famine and high mortality to have declined. That descriptions of cholera appear to have disappeared from the common vocabulary and that past cholera epidemics are now referred to as diarrhea epidemics are testaments to effective public health campaigns against diarrhea. As one participant remarked:

In earlier times, when there was diarrhea in the village, people would be extremely worried as soon as they heard about it. People could not get any nursing, nor did they have access to medical facilities. If smallpox appeared in the village, nobody would walk through [it]; they would have no medical help. They would die just like that. Now we have medicines and medical facilities for those conditions, and people survive.

Another respondent made an even more direct connection between survival and public health interventions:

Earlier, diarrhea was a fatal disease, but now with the help of saline [oral rehydration salts] the disease can be easily controlled.

Box 5 Focus-group participants' stated reasons for the perceived decline in adult survival: Stress, lifestyle changes, and moral degeneration

Now people are having more tension in life. There are medicines for many diseases, but there is no medicine for tension.

Now, in our country, the numbers of bad people are greater.

Now one thinks in terms of self only; [a man] is happy if he can fill his stomach, and he will not think about others.

With the growth of population, the number of thieves and robbers also will increase.

In earlier times, people used to be honest; they never used to tell lies or steal others' belongings. Those were the days of truthfulness.

People do not live long; I mean they are unholy.

One is supposed to take food at 8 o'clock in the morning, but we are delaying the meal to 12 noon. Some do not eat because they don't have any food. Fish and meat may not be available.

People are dying of heart attacks, cancer, adulterated food, and nonavailability of proper medical facilities. 


\section{Box 5 (continued)}

When elders suffer from disease, they cannot go for treatment; hard labor and worry kills them.

Suppose when one is sick, he or she does not go to a doctor, does not consult a doctor or take medicines. That person may say that the money [that would have been spent on a doctor] can be used to feed children. That is why adults are dying.

Yes, they are dying early because they are more addicted to heroin, ganja, and alcohol; earlier they were not addicted.

Now with more education, people have become more inclined to take ganja, liquor, and so forth. The young educated circle are more prone to these vices; that is why they are dying early.

Presently, let us say, 80 percent of the people have diseases. They keep on suffering from gastric trouble, coughing and colds, fever, [and other illnesses].

Box 6 Focus-group participants' statements about the relative abundance of food in the past

There were enough fish in the ponds; now they are not there.

Earlier, there were fewer men; everyone had cows on their own land. People used to get fresh milk and food; they were stronger and lived longer.

In earlier times, the population was smaller, more land was available, and there was an abundance of milk and fish. That is why people could eat well and live longer. But nowadays, we get neither milk nor fish, and there is so much poverty.

Earlier, people used to drink milk and eat pure food in large quantities, but at present that is not possible.

\section{DISCUSSION}

What factors might affect the collective assessment of long-term mortality trends in Bangladesh and West Bengal? A review of the literature suggests, on the one hand, that the memory of famines and disease epidemics of catastrophic proportions plays a strong role. Mortality resulting from famines and epidemics in this region has motivated considerable 
research interest. Five famines occurred in rapid succession in the nineteenth and twentieth centuries, "each of which probably caused several million excess deaths" (Dyson 1991:6). Devastating cholera epidemics, occurring even more frequently, also have been the subject of research (for example, see Arnold 1986). These calamities of the past century or so likely have contributed to a sense of heightened risk and insecurity and to a general perception that survival is threatened. The popular perception of increased mortality also may have been influenced by the depiction of these events in works of art and literature. ${ }^{2}$

On the other hand, Greenough (1983:32) has explored the role of "vivid memories of past starvation" in informing notions of scarcity and risk among peasant populations in Asia. He examines folklore and mythology and argues that Bengali belief systems and social values are rooted in assumptions of abundance and indulgence rather than of bare subsistence. He cites frequent references in the literature of nineteenth- and twentieth-century Bengal to a past that was characterized by benevolence and plenty.

These two sets of writings suggest to us that respondents' views of the present-day quality of life as compared with that of the past depends on which period of the past they are thinking of. If the short-term past is the reference point, the respondent might be inclined to focus on famines and epidemics and conclude that the present is better. If the past of traditional mythology depicting a golden age of plenty is what the respondent envisions, the present can only seem poor by comparison.

In this study, rural focus-group participants unambiguously perceived major declines in infant and child mortality and attributed these declines to factors that are consistent with the assessment of experts concerning the trends and causes of death. Their perception of adult mortality, which has also declined considerably in recent years, stands in sharp contrast, however. Respondents clearly believe that adult mortality has increased because of a gradual degradation of the quality of the food they eat and of the lives they live. This assessment is evidently not informed by respondents' perceptions of an increasing threat of catastrophic events such as famines and epidemics; in fact, some even noted that the incidence of such events had lessened in recent years.

Instead, the respondents seem to be comparing present conditions with a traditional concept of a past characterized by general well-being and proper behavior. ${ }^{3}$ Although they mentioned ingesting poisonous food and breathing polluted air, other emerging threats to health were conspicuous by their absence. The focus-group discussions were conducted during a time when the health consequences of a high level of arsenic in drinking water was the subject of large public-awareness campaigns in Bangladesh and West Bengal. By their responses to specific questions about these messages, participants revealed that they were well aware of the threat posed by arsenic. No mention of this threat to life was made during the discussions of mortality trends, however. Similarly, most respondents had heard about HIV/AIDS on radio and television, but they did not mention this pandemic as a cause of increased mortality. 
The literature about risk perception offers a partial explanation of respondents' inaccurate assessments of adult mortality trends. Respondents may have reported their opposing perceptions of child and adult mortality because the reduction of infant and child mortality is easier to observe than is change in adult mortality levels. Although mortality is high among the elderly, it is generally low for the middle age ranges, and changes in it may be more difficult to perceive. A second, more subjective reason might be the weight attached to the timing of deaths. Deaths of infants and children are considered untimely and unnatural and are, therefore, given greater weight relative to deaths of older people, which may be considered more acceptable.

The memory of past famines and epidemics may continue to inform respondents' evaluations of child mortality in the present. Demographers have debated the demographic consequences of famine, arguing that, by and large, they are not great (Watkins and Menken 1985; Dyson 1991). As Cain and Bongaarts (1982) suggest, however, a distinction must be made between the short- and long-term effects of such crises. Although the changes in fertility, mortality, and population growth that follow even large famines may be short-lived in the context of larger demographic trends, in the longer term famines may still put a brake on fertility decline because of the heightened sense of risk that they evoke. As long as famines and epidemics contribute to a psychological climate of risk and uncertainty, they affect expectations about the survival of offspring and about one's own continued existence.

The results of this study suggest that the disjuncture between perceptions of child and adult survival prospects may, in fact, have helped to sustain fertility decline. If more children are expected to survive to maturity, parents can afford to have fewer offspring. The perceived decline in adult survival may be an additional boost to fertility decline because if people do not expect to live as long as their forefathers did, they may also be less concerned about having children to support them in their old age.

Both research and popular literature emphasize that more people survive to much older ages today than in the past. The typical alarmist view is expressed as a concern with rising dependency ratios and with rising costs of medical and social support for these unprecedented numbers old people, not only because more elderly people are alive today than at any time in human history (because more of them have survived childhood than ever before) but also because within each adult age group, a much higher proportion than ever before now survive into the next age group.

The evidence presented here suggests that uneducated villagers in Bangladesh and West Bengal are profoundly skeptical about the very developments in agriculture that have helped to boost food production in order to sustain large populations on a limited land mass. The views they express do not reflect the human tendency to glorify the past; these villagers declare unambiguously that children's rate of survival today is appreciably better than before. Only adults, however, appear to them to be dying off more rapidly than in the past. Chatterjee's (1998) analysis of elite perceptions suggests that this view is the product of a profound distrust of modernity, particularly of imported modernity associated with colonialism. The respondents in the study also make the association of modern technologies 
alism. The respondents in the study also make the association of modern technologies and lifestyles with imported goods and ideas. Conceivably, these perceptions among villagers may be influenced by the views of the elite; they may, in fact, be an example of social diffusion. These long-standing views among the elite permeate popular thought by means of written and oral storytelling and song. Social reformers and activists deliberately use the distrust of modernity to promote specific objectives. For example, advocates for the environmental movement in Bangladesh have argued against importing agricultural technology and encourage a "back to nature" lifestyle. The distinctions respondents make between child and adult mortality may, however, demonstrate that even the most influential ideas holding sway for long periods are subject to "reality checks." No amount of disapproval of modern lifestyles and methods of food production can blind villagers to the awareness that more children are surviving to maturity now than have in the past.

Our puzzling findings raise other possibilities that we are unable to explore with our data but that are, nevertheless, worth mentioning for discussion and for future research. All our interviews were conducted with adults. These adults, as mentioned above, have seen less and less evidence of high levels of infant and child mortality. Moreover, they have also seen much evidence of direct action taken to reduce child mortality through vaccination programs, antenatal-care programs, and other health-care initiatives. At the same time, they see little direct evidence of a medical system that is proactively caring for the elderly. Additionally, as adults, they belong to a category that is more exposed than children are to the deaths of the elderly — of their parents and of the parents of their peers - and this exposure may color their perceptions of the rate at which the old are dying. If we interviewed children with relatively young parents, they might view adults as living long.

Increased adult mortality may also be inferred from the rising morbidity and disability that accompany increasing longevity in poor countries. Because the old are living longer, our respondents may be aware of greater numbers of senile, ill, or physically impaired adults than in times past. This increased presence of the infirm might lead respondents to equate the worsened quality of life among the elderly with generally higher mortality risks among this age group. We are intrigued by a frequent assertion in our interviews that in the past, people lived to be 80,90 , and 100 . We wonder whether improving numeracy accounts for the feeling that things are worse now. These improbable ages of people in the past are based on hearsay, on numbers generated in a past society in which precise biological age was not known or necessary to know but was imputed from appearance and seeming wisdom. Today, the respondents might be much better informed about the age of someone who has died. If a recently deceased man is known to have been 60 years old at his death, he will be thought to have died young in comparison with his lucky forebears.

Finally, in considering the opinions about morality implicit in evaluations of changes in adult mortality, we wonder whether respondents' perception that adult mortality is increasing is related to their apprehensions about modern lifestyles and the insecurities such lifestyles bring along with their seductive aspects. Children cannot be held morally 
accountable. Therefore, it is legitimate to appreciate the advantages in survival that the present age has conferred on them. These advantages include the straightforward application of medical technology and good government, which suggest nothing concerning children's acquiescence in this modernity.

These are matters to investigate in future research on popular perceptions. Demographic research sets much store by the idea of "perceptions." We were surprised, indeed, that we could find little empirical interest in the subject.

\section{NoTES}

1 In settings where the majority of respondents are illiterate, oral rather than written history is the frame of reference; and in discussing the past, people are not willing to venture far beyond two generations. A common time referent for the past is "bap-dadar amol" (father's and grandfather's time).

2 A number of popular films, paintings, and books keep alive the images of famine in Bangladesh and West Bengal. The most celebrated of such films include Ashani Shanket (A Distant Thunder) directed by Satyajit Ray and Akaler Shandhane (In Search of Famine) directed by Mrinal Sen. A series of sketches by Zainul Abedin (1914-76) based on his travels in rural Bengal during the famine of 1947 are powerful and widely reproduced depictions of the disaster.

3 These ideas of a world in decline in general and of moral culpability in particular may also have their genesis in larger, but often subconscious, Hindu belief that the present time is the Dark Age, the Kali Yuga, during which life is short and hard, righteousness is lost, and evil rules. Although this, the fourth and final time-cycle of the universe in Hindu cosmology, is believed to have begun in 3102 B.C., Kali Yuga in the popular imagination is often conveniently described as an unhappy present age, compared with a happier, but much more recent (than 5000 years) past.

\section{REFERENCES}

Amin, Sajeda. 1995. "The expanded program on immunization in Bangladesh," in Evaluation and Impact of Health Interventions. Ed. Hoda Rashad. London: Oxford University Press. Pp. 397-414.

Amin, Sajeda, Alaka Malwade Basu, and Rob Stephenson. 2002. "Spatial variation in contraceptive use in Bangladesh: Looking beyond the borders," Demography 39(2): 251-268.

Arnold, David. 1986. "Cholera and colonialism in British India," Past and Present 0(113): 118151.

Bairagi, Radheshyam, Santosh Chandra Sutradhar, and Nurul Alam. 1999. "Levels, trends and determinants of child mortality in Matlab, Bangladesh, 1966-1994," Asia-Pacific Population Journal 14(2): 51-68. 
Basu, Alaka Malwade and Sadeja Amin. 2000. "Conditioning factors for fertility decline in Bengal: History, language identity, and openness to innovations," Population and Development Review 26(4): 761-794.

Cain, Mead and John Bongaarts. 1982. "Demographic responses to famine," in Famine. Ed. Kevin M. Cahill. New York: Orbis Books. Pp. 44-49.

Chatterjee, Partha (ed.). 1998. “Our Modernity.” The Present History of West Bengal: Essays in Political Criticism. Delhi: Oxford University Press.

Cleland, John. 2001. "The effects of human survival on fertility: A reassessment," Population and Development Review 27(supplement): 60-92.

DHS + DIMENSIONS. 2000. "Survival chances increase for children in Bangladesh," Fall(2): 3.

Dyson, Tim. 1991. “On the demography of south Asian famines: Part I," Population Studies 45(1): $5-25$.

Greenough, Paul. 1983. "Indulgence and abundance as Asian peasant values: A Bengali case in point," Journal of Asian Studies 42(4): 831-850.

Hurd, Michael and Kathleen McGarry. 1995. "Evaluation of the subjective probabilities of survival in the Health and Retirement Study," Journal of Human Resources 30(supplement): S268S292.

International Centre for Diarrhoeal Disease Research, Bangladesh (ICDDR,B). 1991. Demographic Surveillance System-Matlab. Volume 15. Registration of Demographic Events, 1984. Scientific Report No. 67. Dhaka: ICDDR, B.

- 1994. Demographic Surveillance System-Matlab. Volume 21. Registration of Demographic Events, 1990. Scientific Report No. 73. Dhaka: ICDDR, B.

1996. Demographic Surveillance System-Matlab. Registration of Demographic Events, 1993. Dhaka: ICDDR, B.

Koenig, M.A., N.C. Roy, T. McElrath, M. Shahidullah, and B. Wojtyniak. 1998. "Duration of protective immunity conferred by maternal tetanus toxoid immunization: Further evidence from Matlab, Bangladesh," American Journal of Public Health 88(6): 903-907.

Le Grand, Thomas K. and James F. Phillips. 1996. "The effect of fertility reductions on infant and child mortality: Evidence from Matlab in rural Bangladesh," Population Studies 50(1): 5168.

Mirowsky, John. 1999. "Subjective life expectancy in the U.S.: Correspondence to actuarial estimates by age, sex and race," Social Science \& Medicine 49(7): 967-979.

Montgomery, Mark R. 2000. "Perceiving mortality decline," Population and Development Review 26(4): 795-819. 
Mostofa, Golam et al. 1996. Demographic Surveillance System-Matlab. Registration of Demographic Events, 1995. Vol. 27. Dhaka: ICDDR, B.

Ruzicka, Lado T. and A.K.M. Alauddin Chowdhury. 1978. Demographic Surveillance SystemMatlab. Volume 4. Vital Events and Migration, 1975. Scientific Report No. 12. Dhaka: Cholera Research Laboratory.

Samad, Aporn et al. 1979. Demographic Surveillance System-Matlab. Volume 6. Vital Events and Migration, 1977. Scientific Report No. 18. Dhaka: ICDDR,B.

Watkins, Susan Cotts and Jane Menken. 1985. "Famines in historical perspective," Population and Development Review 11(4): 647-675.

World Health Organization (WHO). 2000. $<$ http://www-nt.who.int/vaccines/GlobalSummary/ Immunization.> Accessed 24 October 2003.

—. 2002. World Mortality in 2000: Life Tables for 191 Countries. Geneva: WHO. 


\section{POLICY DIVISION WORKING PAPERS}

If still in print, single copies of up to three working papers from 1989 through 2003 are available free of charge.

Beginning with the 2004 issues, the working papers will no longer be available in print format. Instead they will be distributed electronically. As each new paper is completed subscribers will be notified by e-mail and a link to the paper will be provided.

To subscribe to the Policy Research Division working paper e-mail notification list, or to obtain back issues from 1989 to 2003, please send your request to prdwp@popcouncil.org.

PDFs of recent issues are available at www.popcouncil.org/publications/wp/prd/rdwplist.html

2004

186 Sajeda Amin and Alaka M. Basu. "Popular perceptions of emerging influences on mortality and longevity in Bangladesh and West Bengal."

185 John Bongaarts. "Population aging and the rising cost of public pensions."

184 Mark R. Montgomery and Paul C. Hewett. "Urban poverty and health in developing countries: Household and neighborhood effects."

\section{3}

183 Agnes R. Quisumbing and Kelly Hallman. "Marriage in transition: Evidence on age, education, and assets from six developing countries."

182 Paul C. Hewett, Barbara S. Mensch, and Annabel S. Erulkar, "Consistency in the reporting of sexual behavior among adolescent girls in Kenya: A comparison of interviewing methods."
181 Zachary Zimmer, Linda G. Martin, and Hui-Sheng Lin, "Determinants of old-age mortality in Taiwan."

180 Frank K. Nyonator, J. Koku Awoonor-Williams, James F. Phillips, Tanya C. Jones, and Robert A. Miller, "The Ghana Community-based Health Planning and Services Initiative: Fostering evidence-based organizational change and development in a resourceconstrained setting."

179 John Bongaarts and Griffith Feeney, "Estimating mean lifetime."

178 Elizabeth F. Jackson, Patricia Akweongo, Evelyn Sakeah, Abraham Hodgson, Rofina Asuru, and James F. Phillips, "Women's denial of having experienced female genital cutting in northern Ghana: Explanatory factors and consequences for analysis of survey data."

\footnotetext{
* No longer available as a printed publication. Download electronic file from Web site only.
} 
177 John Bongaarts, "Completing the fertility transition in the developing world: The role of educational differences and fertility preferences."

176 Cynthia B. Lloyd and Paul C. Hewett, "Primary schooling in sub-Saharan Africa: Recent trends and current challenges."

175 James F. Phillips, Tanya C. Jones, Frank K. Nyonator, and Shruti Ravikumar, "Evidence-based development of health and family planning programs in Bangladesh and Ghana."

174 Geoffrey McNicoll, "Population and development: An introductory view."

173 Paul Demeny, "Population policy: A concise summary."

172 Zachary Zimmer, Napaporn Chayovan, Hui-Sheng Lin, and Josefina Natividad, "How indicators of socioeconomic status relate to physical functioning of older adults in three Asian societies."

171 Sajeda Amin and Nagah H. AlBassusi, "Wage work and marriage: Perspectives of Egyptian working women."

170 Ravai Marindo, Steve Pearson, and John B. Casterline, "Condom use and abstinence among unmarried young people in Zimbabwe: Which strategy, whose agenda?"
Zachary Zimmer and Julia Dayton, "The living arrangements of older adults in sub-Saharan Africa in a time of HIV/AIDS."

168 Paul C. Hewett, Annabel S. Erulkar, and Barbara S. Mensch, "The feasibility of computerassisted survey interviewing in Africa: Experience from two rural districts in Kenya."

2002

167* Dominic K. Agyeman and John B. Casterline, "Social organization and reproductive behavior in southern Ghana."

166* Carol E. Kaufman and Stavros E. Stavrou, " 'Bus fare, please': The economics of sex and gifts among adolescents in urban South Africa."

165 Kelly Hallman, Agnes R. Quisumbing, Marie Ruel, and Bénédicte de la Brière, "Childcare, mothers' work, and earnings: Findings from the urban slums of Guatemala City."

164 Cynthia B. Lloyd, Cem Mete, and Zeba A. Sathar, "The effect of gender differences in primary school access, type, and quality on the decision to enroll in rural Pakistan."

163 Barbara S. Mensch, Wesley H. Clark, and Dang Nguyen Anh, "Premarital sex in Vietnam: Is the current concern with adolescent reproductive health warranted?"

* No longer available as a printed publication. Download electronic file from Web site only. 
162 Naomi Rutenberg, Carol E. Kaufman, Kate Macintyre, Lisanne Brown, and Ali Karim, "Pregnant or positive: Adolescent childbearing and HIV risk in South Africa."

161 John Bongaarts, "The end of the fertility transition in the developing world."

160* Julia Dayton and Martha Ainsworth, "The elderly and AIDS: Coping strategies and health consequences in rural Tanzania."

159 Carol E. Kaufman, Shelley Clark, Ntsiki Manzini, and Julian May, "How community structures of time and opportunity shape adolescent sexual behavior in South Africa."
158 Geoffrey McNicoll, "Demographic factors in East Asian regional integration."

157 Zachary Zimmer and Sovan Kiry Kim, "Living arrangements and socio-demographic conditions of older adults in Cambodia."

156 John Bongaarts and Griffith Feeney, "How long do we live?"

155 Zachary Zimmer, Linda G. Martin, and Ming-Cheng Chang, "Changes in functional limitations and survival among the elderly in Taiwan: 1993, 1996, and 1999."

* No longer available as a printed publication. Download electronic file from Web site only. 